\title{
THE INFLUENCE OF ORGANIC MATTER ON THE EFFICACY OF CERTAIN DISINFECTANTS.
}

By M. WYNTER BLYTH, B.A., B.Sc., F.I.C.

(Read at the Meeting, April 4, 1903.)

THE influence of organic matter on chloride of lime, potassium permanganate, and other oxidizing disinfectants, has been studied by several workers. The phenol class has, however, received no such attention, and the statements that the germicidal power of this or that disinfectant " is maintained, no matter what form of organic matter it is mixed with," appear to have been accepted without question. 
In a paper on the "Standardization of Disinfectants" (Journal Royal Sanitary Institute, October, 1903, 424), S. Rideal and J. T. Ainslie Walker call attention to the importance, when estimating germicidal value, of keeping the amount of culture in the diluted disinfectants constant, and give an example of the difference produced by increasing the quantity of culture in the dilution, but they do not state what class of disinfectant was used. R. H. Firth and Allan Macfadyen, in a report (Journal Royal Sanitary Institute, February, 1906, 17) to the committee appointed by the Royal Sanitary Institute to inquire into the desirability of establishing a standard bacteriological method for determining the efficiency of disinfectants, record some experiments on phenol disinfectants in which germicidal values were determined in fæces and in urine, and H. R. Kenwood and R. T. Hewlett (Journal Royal Sanitary Institute, February, 1906, 1) have used an almost identical method. The fæces and urine were used, however, with the object of making the experiments represent in a modified form the conditions which might be met in practical disinfection, and not with the idea of determining the actual influence of organic matter, as neither the weight nor the composition of the fæces and urine are recorded.

In reporting to a committee of the Sanitary Institute early in 1903, I drew particular attention to the influence which even small quantities of organic matter have on the comparative germicidal value of disinfectants of the phenol class, and the experiments recorded here are a continuation of the work begun at that time.

The disinfectants dealt with here are phenol, cresylic acid (a mixture of ortho, meta, and para), Izal, Cyllin, resorcin, and pyrogallic acid.

In attempting to determine the influence of organic matter on these disinfectants, I have thought it best to take a fluid rich in organic matter, and containing such substances as might be met with in practical disinfection, although I do not intend to deal in this paper in any way with practical disinfection.

Such a fluid is milk. Milk has the obvious advantages of containing the three great classes of organic matter-i.e., carbohydrate, fat, and proteid-as well as organo-mineral salts, in the combinations and physical condition in which they have been presented to us by Nature. The organic and mineral matter can not only be determined with great accuracy, but the relative quantities can to a large extent be varied at will.

First, the "carbolic acid coefficients" of the various disinfectants were determined by a modification of the Rideal-Walker method (Journal Royal Sanitary Institute, October, 1903, 426), the modification being 6 drops of a twenty-four hours old culture at $37^{\circ} \mathrm{C}$. of $B$. coli communis, added to 10 c.c. of the diluted disinfectant, in place of 5 drops of a twenty-four hours old culture of B. typhosus, added to 5 c.c. of the diluted disinfectant. The larger quantity of disinfectant was taken for the sake of convenience and accuracy, and the smaller quantity of broth-culture to insure the introduction of as little organic matter as possible. The rest of the details of the Rideal-Walker method were adhered to, except that the temperature during the majority of the experiments was low-i.e., $12^{\circ} \mathrm{C}$. This temperature gives low results with at least one disinfectant, but does not affect the comparative results with organic matter. Having determined the carbolic coefficients in water, the coefficients were determined in 5 c.c. of milk diluted to 10 c.c. with various dilutions of the 
disinfectants. The milk used was both milk with all its cream and separated milk, and the composition of each batch was determined.

The milk used in the results given below had an average composition of-

$\begin{array}{llcccc} & & \text { Fat. } & \text { Milk-sugar. } & \text { Protcids. } & \text { Asl. } \\ \text { Full milk } \ldots & \ldots & 3 \cdot 6 & 4 \cdot 7 & 3 \cdot 4 & 0 \cdot 74 \\ \text { Separated milk } & \ldots & 0 \cdot 3 & 4 \cdot 8 & 3 \cdot 6 & 0 \cdot 78\end{array}$

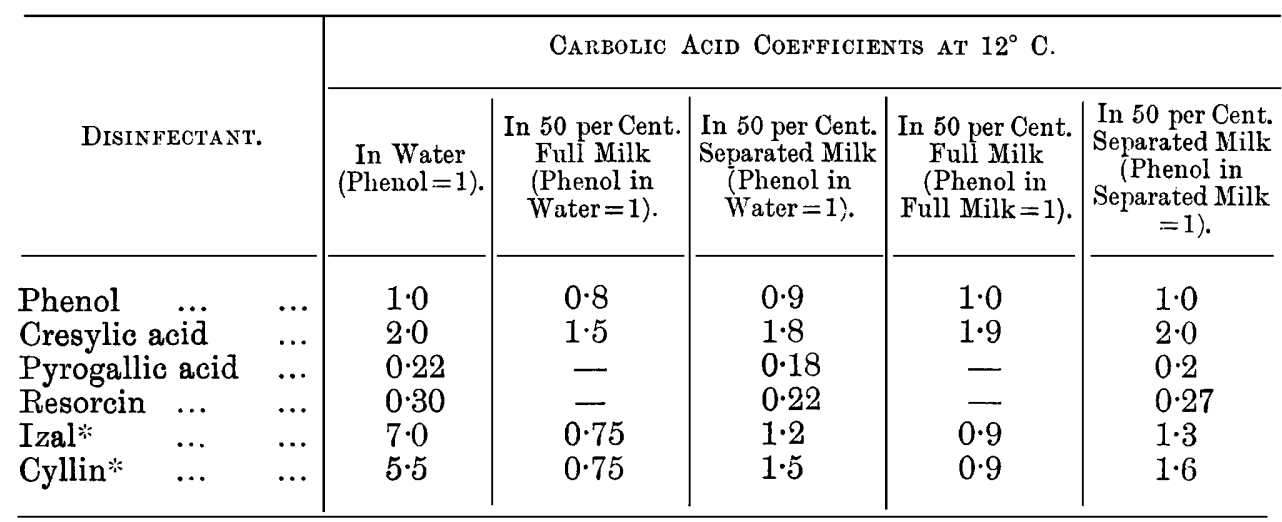

It will be seen from these results that the constituents of milk have a very marked influence on the germicidal value of the phenol disinfectants, and further experiments showed that the lowering in comparative and actual germicidal value is proportional to the amount of milk constituents present. Thus, in some experiments with Izal a solution of 1 of Izal in 100 water produced sterility in ten minutes when 18 per cent. of milk was present, but not when 36 per cent. of milk was present; $1: 66$ Izal produced sterility in ten minutes with 36 per cent. of milk, but not with 72 per cent.; $1: 50$ Izal produced sterility in thirty minutes with 72 per cent. of milk, but not with 85 per cent. The influence of milk constituents on phenol itself is not nearly so marked as on the cresols and those disinfectants containing the higher phenols, so that as we introduce more milk into the dilutions we get a progressive fall in the comparative carbolic acid coefficient.

The Influence of Fat.-If we compare the coefficients in full milk and separated milk, it will be seen that the introduction of fat causes, according to the disinfectant, a more or less pronounced fall in the coefficient. When separated milk is used, we have slightly more of each organic constituent present except fat and a little more mineral matter than we have when full milk is used. So that if fat has no influence we should expect the coefficient in separated milk to be lower than in full milk; but the reverse is found to be the case. It was further found that when a milk rich in fat was taken, a lower coefficient was obtained than with the milk containing less fat. Thus with Izal a coefficient (phenol in water =1) of 0.8 was obtained with a milk containing 3.5 per cent. of fat and a coefficient of 0.5 (phenol in water $=1$ ) with $4 \cdot 2$ per cent. of fat.

The influence of fat is probably purely physical, some of the emulsified oils in

* The proprietary names of two disinfectants on the market. 
cresylic acid, Izal, and Cyllin being dissolved by the fat, and removed from contact with the organism. This view is supported by the fact that a 1 per cent. solution of Cyllin, after shaking up with one-third its volume of olive oil, gave a coefficient of under 3 at $20^{\circ} \mathrm{C}$. (phenol in water $=1$ ), as compared with an original coefficient of $7 \cdot 7$ at $20^{\circ} \mathrm{C}$.

The Influence of Milk-Sugar.-The coefficients of the disinfectants were taken in 2.5 per cent. of milk-sugar. Although in some cases there was a slight lowering of the coefficient, yet the effect of this quantity of milk-sugar is so small that it may be neglected.

The Influence of the Mineral Constituents.-The ash from 5 c.c. of burnt-up milk had apparently, when shaken up with 10 c.c. of sterile water, no appreciable influence on the coefficients. This experiment, however, proves little, since the constituents of the ash are not in the same combinations as in the natural milk.

The Influence of Proteids. - The only constituents of the milk left which are likely to influence the coefficients are the casein and albumin. If we admit that the milksugar and ash have little, if any, influence, and that the fat only accounts for a portion of the loss, we must conclude that the proteids are the main factor in the lowering of the coefficients. This view is supported by the fact that in a 1 per cent. solution of serum-albumin the coefficient of Cyllin was found to be under 3 at $12^{\circ} \mathrm{C}$. And in some experiments on gelatin solutions the presence of 2.5 per cent. of gelatin reduced the coefficient of Izal, taken at $40^{\circ} \mathrm{C}$., from 7 (in water) to 4.5 (in gelatin. Phenol in water at $40^{\circ} \mathrm{C} .=1$ ). In the same way with gelatin the coefficient of Cyllin was lowered from $8 \cdot 4$ to $5 \cdot 3$.

Temperature.-In connection with the determination of the coefficients in gelatine at $40^{\circ} \mathrm{C}$., the influence of temperature on the three disinfectants, phenol, Izal, and Cyllin, was determined, when an interesting difference was observed. All of them are naturally more active at the higher temperatures, but phenol and Izal increase in activity in much the same ratio, with the result that the coefficient of I zal remains at about 7 over a wide range of temperature. On the other hand, the activity of Cyllin increases, especially at first, more rapidly than that of phenol; consequently there is a rapid rise in the coefficient.

Carbolic acid coefficients of Cyllin at various temperatures :

$\begin{array}{lllccc}\text { Temperature } & \ldots & 8^{\circ} \mathrm{C} . & 12^{\circ} \mathrm{C} . & 20^{\circ} \mathrm{C} . & 40^{\circ} \mathrm{C} \text {. } \\ \text { Coefficient } & \ldots & 5 & 5.5 & 7 \cdot 7 & 8 \cdot 4\end{array}$

These differences are probably due to the variations in the size of the oil globules at different temperatures, Izal, being supplied in the form of a fine emulsion, not being influenced to any great extent by variations in temperature.

Poisonous Properties and Germicidal Value.-Although it is easy to understand how a substance may be fatal to a highly complex animal organism and yet harmiess to vegetable organisms, it is not so easy to understand why substances such as Izal and Cyllin are so deadly to "naked" micro-organisms in water and comparatively harmless to animal life, while phenol is much less fatal to naked micro-organisms and yet very toxic to animals.

There seems to be a certain amount of confusion in literature as to the relative 
poisonous properties of phenol, the cresols, and the di- and tri-hydroxyl phenols. Thus I find it variously stated that resorcin is more poisonous than phenol, and that it can be taken in relatively large doses. Pyrogallic acid is stated to be more poisonous than phenol, but I find that it is considerably less poisonous to small animals, which can be immersed in the liquid. According to Karl Tollen's (Archiv f. experiment. Path. u. Pharm., Bd. ii., S. 239) experiments on cats, mice, and frogs, meta-cresol is less poisonous and para-cresol more poisonous than phenol, while ortho-cresol is as poisonous as phenol to cats and mice, but less so to frogs. For the purpose of seeing if there is any connection in the phenol class between poisonous properties and germicidal value, instead of taking the action on man or large animals, it is, I think, better to take some small organism, such as a worm (Lumbricus herculeus), which can be placed under the same conditions as the micro-organisms.

In some experiments with worms of equal weight, I found that the time taken to kill them by means of 5 per cent. solutions was as follows :

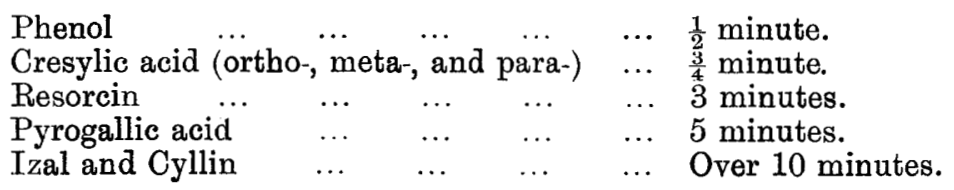

Taking phenol, resorcin, and pyrogallic acid, the poisonous nature seems to be decreased as we introduce hydroxyl groups, and is directly proportional to their germicidal value. Further, these compounds suffer very little loss in germicidal value in the presence of albumin. Taking phenol, cresylic acid, Izal, and Cyllin, their germicidal value appears to be in inverse proportion to their poisonous nature; but phenol and cresylic acid, which lose but little germicidal value when mixed with milk, are highly toxic; while Izal and Cyllin, which lose about 80 per cent. of their germicidal value in milk, are but little toxic. Both the toxic and germicidal action of these compounds may be explained if we consider that the higher phenols act on the delicate " naked" organisms and unite with the "labile" albumin of the protoplasm, the act of union killing the organism, and converting the albumin into a more or less nontoxic compound. If other albumin is present, a certain quantity of the higher phenols unite with this, leaving less poison to unite with the "labile" albumin. The albumin-phenol compound formed would appear to be more poisonous as we descend from Izal to phenol, and possibly equally poisonous in the mono-, di-, and tri-hydroxy phenols; and it is due to this fact that these last-mentioned bodies maintain their germicidal value in the presence of organic matter. The supposition that a poisonous albumin-phenol compound is formed receives support from the fact that, although resorcin gives a copious precipitate with albumin, it suffers but little loss of germicidal value.

Summary.-Disinfectants containing the higher phenols suffer great loss of efficacy when mixed with (1) fat, (2) albumin, and (3) fæces and urine (see Kenwood and Hewlett, Public Health, February, 1906, and April, 1906).

The germicidal value of a disinfectant acting on a "naked" organism gives little, if any, indication of its value in the presence of organic matter. 
It appears impossible in the phenol class to combine a low toxic value with a high germicidal value in the presence of much organic matter.

\section{Discussion.}

The President (Mr. Bevan) having invited discussion,

Professor Kenwood said that Mr. Wynter Blyth's paper afforded further evidence of the insufficiency of any method which aimed at obtaining the germicidal value of a particular preparation when that method dealt with naked organisms, for it demonstrated how largely the introduction of organic matter affected the case at issue. It was that very circumstance that made necessary the revision of most of the conclusions based on the work on disinfectants during the last fifteen or twenty years; for a very large proportion of that work had either been performed upon naked organisms, or had been carried out according to methods which at the present day were open to criticism. The author had referred to Messrs. Rideal and Walker's method of standardizing disinfectants, and had said that in his opinion the flaw in that method was the fact that it did not take into account the effect which the associated organic matter had upon the disinfectant. With that opinion he (the speaker) and many others were in agreement. By that method it had been shown that potassium permanganate was about the most efficient disinfecting agent possible, whereas it was well known that when a large amount of organic matter was present the use of permanganate as a germicidal agent was unsatisfactory, because it acted preferentially on the dead (and more especially the putrescent) organic matter, and was therefore often used up by associated dead organic matter before the living germs were destroyed. Although, however, the Rideal-Walker method suffered from that defect, he, in common, he believed, with Mr. Wynter Blyth, should like to express his appreciation of a valuable suggestion, for he thought that on the lines indicated by Messrs. Rideal and Walker a method of standardization might be arrived at which would take into account the effects produced by the association of the germ with organic matter. The method, however, as originally proposed, and as applied at any rate up to the present, was certainly defective and unacceptable. The results of his own experiments, in conjunction with Professor Hewlett, upon typhoid fæces from one of the large fever hospitals in London were quite in accord with those obtained by Mr. Wynter Blyth. They had found that the coefficients obtained with the naked organisms were totally different from those obtained when they sought to attack the germ in its usual environment of a relatively enormous quantity of organic matter. Their difficulty had been to find a standard medium in which the organisms could be planted, and which would present the average difficulty of attack which is encountered when any of the natural media of fæces, urine, sputum, pus, etc., was present. The objections to working with fæces and pus (with the latter of which he was now making some experiments) were, of course, considerable, and he believed that really it was not necessary to use such media as these, but that it ought to be possible to devise a standard medium presenting similar obstacles to attack by disinfectants. The author had pointed out that milk as a standard medium afforded the advantage that its exact composition could be readily ascertained. Certainly milk presented some advantages in this respect, but probably Mr. Wynter Blyth would agree that 
it would not be entirely satisfactory as a standard organic medium. Its levelling effect was too great, because it was greater than that of fæces, and greater, he believed it would be found, than that of pus. The experimental results given in the paper were very interesting, and he should like, in conclusion, to say that the author had asked him, as his results were rather startling, to check one or two of them. After considerable experience of the action of these disinfectants, he was certainly surprised to hear that the effect of adding the organisms to milk with 50 per cent. of water was to reduce their germicidal coefficients so largely; but on repeating the author's experiment with Izal in comparison with phenol, working with the typhoid germ, he found the carbolic acid coefficient of Izal (which was about 9 by the Rideal-Walker method) to be exactly 1 . That was practically in agreement with the author's figure. He had no doubt that the results obtained with regard to the other disinfectants were quite correct, though he had not had time to repeat the author's experiments with these.

Dr. RIDEAL said that when the relative value of disinfectants was determined in a medium containing organic matter the differences shown between them were much smaller than those shown when water only was used. In other words, in the presence of organic matter the disinfectants were not differentiated from one another so markedly as in the absence of organic matter. The test which Mr. Walker and he had suggested was put forward as a method for separating the disinfectants from one another-not for bringing them close to one another; and it was not put forward as a method for determining their relative value for any specitic purpose. It might, of course, be said that disinfectants as a rule were used in presence of organic matter. They were seldom used, however, in milk; so that from that point of view milk was just as objectionable as water, and he ventured to think that this applied even to urine and fæces, for it was seldom, after all, that these had to be disinfected by chemical means. In comparing disinfectants from a particular point of view, however, the first thing to be done was to find out how far apart or how close together the different disinfectants were in some neutral, uniform medium, and they had chosen water as a definite thing that could be reproduced in any laboratory. Every chemist, of course, knew without any bacteriological test that potassium permanganate, chlorine, bromine, and so on, were useless in presence of large quantities of organic matter; but it must also be recollected that disinfectants were required in cases where there was not a very large amount of organic matter, such, for instance, as the very important problem of the sterilization or disinfection of water-supplies; and it would be absurd to say that because bleaching powder showed a low germicidal value when tested in fæces or in milk, it therefore would be useless for disinfecting the water-supply in a case like that of the recent typhoid epidemic at Lincoln. It seemed to him, therefore, that even greater objections might be urged against the media suggested by Professor Kenwood and Mr. Wynter Blyth than against water, until one knew what the disinfectant was going to be used for. The question of the toxic value of disinfectants was a very interesting one, but, baving regard to the enormous differences which appeared to exist between the effect on germs and on worms, and to the still greater differences which presumably would be found when the effects on human beings were considered, he should not 
himself like to accept the results of Mr. Wynter Blyth's experiments on worms as indicating either the relative value or the poisonous nature of the disinfectants he had experimented with. With regard to the effect of temperature, Mr. Walker and he had found that as a rule the coefficient rose when the temperature was increased.

Mr. Wynter BLYTh said that he had not intended in any way to attack the Rideal-Walker method, but simply to put down the results of his experiments, which showed that when these disinfectants were mixed, not only with milk, but with albumin, gelatin, and fat, the coefficients were considerably lowered. He did not suggest for a moment the adoption of a standard medium in the form of milk. $\mathrm{He}$ had taken milk because he thought that, as it was easily analysed and could be varied in composition at will, it would give some idea of the effect of each constituent. $\mathrm{He}$ thought that the constituent which had the greatest influence was the albumin, and surely albumin was a body which had to be dealt with almost invariably in practical disinfection. He must say that he failed to understand what was meant when Dr. Rideal said that the Rideal-Walker method was for the purpose of separating disinfectants. Did he mean that it was intended to mislead people as to their true value? With regard to the toxic values, it perhaps would have been better to use the various solutions in exactly the same way as in determining the germicidal values, so as to ascertain how much of each was required to do the same amount of work. That would have given their toxic values as applied to worms. These figures, however, did give some idea of the toxic values as applied to a living animal immersed in the liquid under the same conditions as a micro-organism. Some of the statements on this point in the books were very conflicting. For instance, he found that in Dr. Rideal's book resorcin was stated to be not at all poisonous even in large doses, while in his father's book on "Poisons" it was said to be very much more poisonous than phenol. He had therefore had to make experiments on his own account, as he wanted to trace, if possible, some connection between germicidal value and toxic value. He thought that some such connection must exist, but the point required much further investigation. 